\title{
Composite Ganglioneuroblastoma, Stroma-Dominant and Stroma-Poor
}

National Cancer Institute

\section{Source}

National Cancer Institute. Composite Ganglioneuroblastoma, Stroma-Dominant and

Stroma-Poor. NCI Thesaurus. Code C42060.

A neuroblastic tumor characterized by the presence of a ganglioneuroblastoma component and the formation of Schwannian stroma which is the predominant component of the tumor volume. 